\title{
REMOÇÃO DO CORANTE AMARELO DE TARTRAZINA SOBRE ADSORVENTE OBTIDO DE LODO DE ESGOTO
}

\author{
Daniel Salustiano Costa Neto ${ }^{1}$; Tereza Simonne Mascarenhas Santos ${ }^{2}$ \\ 1. Bolsista PIBIC/Fapesb, Graduando em Licenciatura em Química, Universidade Estadual de Feira de Santana, e- \\ mail: salustianocosta@hotmail.com \\ 2. Orientador, Departamento de Ciências Exatas, Universidade Estadual de Feira de Santana, e-mail: \\ tereza.simonne@gmail.com
}

PALAVRAS-CHAVE: Lodo de esgoto; Carvão ativado; tartrazina.

\section{INTRODUÇÃO}

Dentre os tipos de resíduos gerados por atividade industrial, os têxteis e alimentícios ganham destaque por utilizarem uma grande variedade de corantes e pigmentos para dar cor aos seus produtos. A remoção destes corantes do meio aquoso é de difícil tratamento, pois são moléculas recalcitrantes, resistentes a digestão aeróbia, estáveis a agentes oxidantes, principalmente quando estão em concentrações baixas (Banerjee et al, 2013). Dentre os métodos para remoção desse corante, a adsorção ganha destaque pela sua ampla variedade de adsorventes de baixo custo, o que faz deste método eficiente e econômico no tratamento de água (Dotto, 2011). O objetivo deste trabalho foi avaliar a remoção do corante amarelo tartrazina utilizando adsorvente obtido a partir do lodo de esgoto.

\section{METODOLOGIA}

Amostra CEC01: O adsorvente CEC01 foi obtido a partir do lodo de esgoto da Estação de Tratamento Contono, ETE Contorno, Feira de Santana, após 08 dias de permanência no leito de secagem. A mostra foi pirolisada em forno tubular a uma taxa de aquecimento de $10^{\circ} \mathrm{C} \cdot \mathrm{min}^{-1}$ sob atmosfera inerte (argônio) até $550^{\circ} \mathrm{C}$. O lodo permaneceu nesta temperatura até $60 \mathrm{~min}$. O adsorvente foi denominado CEC01.

Amostra CES04: O adsorvente CEC04 foi obtido a partir do lodo de esgoto da Estação de Tratamento Subaé, ETE-Subaé, Feira de Santana, após 32 dias de permanência no leito de secagem. A mostra foi pirolisada em forno tubular a uma taxa de aquecimento de $10^{\circ} \mathrm{C} \min ^{-1}$ sob atmosfera inerte (argônio) até $350^{\circ} \mathrm{C}$. O lodo permaneceu nesta temperatura até $30 \mathrm{~min}$. $\mathrm{O}$ adsorvente foi denominado CES04.

A amostra de lodo de esgoto LEC01 foi analisada por espectroscopia vibracional na região do infravermelho com transformada de Fourier (FTIR). LEC01 e LES04 foram analisadas por análise termogravimétrica, utilizando um aparelho Shimadzu TG50 no intervalo de temperatura de 25 até $1000^{\circ} \mathrm{C}$, atmosfera de argônio, fluxo de $50 \mathrm{~mL} \mathrm{~min}^{-1}$, taxa de aquecimento de $10^{\circ} \mathrm{C} \cdot \mathrm{min}^{-1}$.

Isoterma de Adsorção

Os ensaios de adsorção foram realizados em banho finito, com soluções de amarelo tartrazina em concentrações variando de 01 a $20 \mathrm{ppm}$. Os experimentos foram realizados adicionando-se $0,05 \mathrm{~g}$ do adsorvente a $10 \mathrm{~mL}$ de solução. As soluções ficaram sob agitação a temperatura ambiente por $60 \mathrm{~min}$. A concentração das soluções do amarelo de tartrazina foi determinada por espectrofotômetro ultravioleta (UV-VIS). 
Para os ensaios com o carvão sintético comercial as soluções de amarelo tartrazina foram preparadas em concentrações variando de 50 a 400 ppm. A adsorção foi avaliada quantitativamente pelos Modelos de Freundlich e de Langmuir.

\section{RESULTADOS E DISCUSSÃO}

Espectroscopia Vibracional na Região do Infravermelho (FTIR): Observa-se as bandas características dos compostos gerados na decomposição da matéria orgânica no lodo de esgoto. A banda na região $1585 \mathrm{~cm}^{-1}-1700 \mathrm{~cm}^{-1}$ pode ser atribuída a estiramentos $\mathrm{C}=\mathrm{C}$ de anéis aromáticos, típicos de materiais carbonáceos. As bandas localizadas na região de $800 \mathrm{~cm}^{-1}$ a $940 \mathrm{~cm}^{-1}$ são atribuídas as vibrações $\mathrm{C}-\mathrm{H}$ fora do plano dos compostos aromáticos. As bandas entre $1665 \mathrm{~cm}^{-1}-1760 \mathrm{~cm}^{-1}$ são características dos ácidos carboxílicos. Esse resultado confirma a presença de vibrações características dos principais constituintes de lodo de esgoto que são proteínas, gorduras, ureia, açúcares, proteína, lipídeos, celulose, lignina, fenóis e taninos.

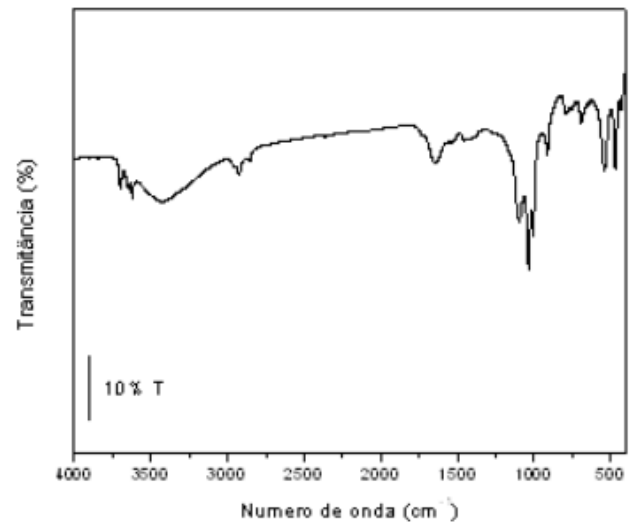

Figura 1 - Espectro de infravermelho da amostra LEC01

Análise Termogravimétrica: A análise termogravimétrica foi realizada para LEC01 e LES04 amostras, em diferentes estágios de estabilização do lodo de esgoto no leito de secagem, Figura 02.

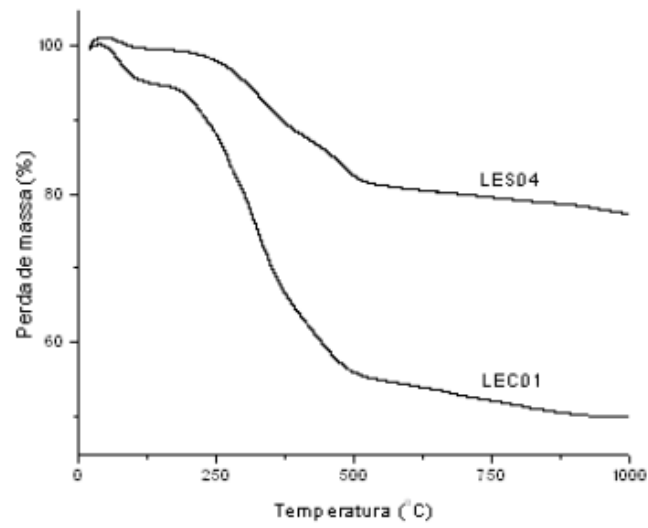

Figura 2 - Resultados da análise termogravimétrica das amostras de lodo de esgoto

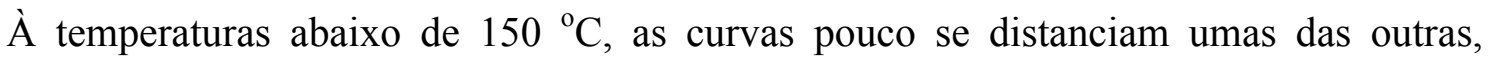
mostrando uma diferença não significativa, e que pode ser atribuída a diferença nos conteúdos de carbono. Com o aumento da temperatura, observa-se que as curvas se distanciam significativamente em pares, com maior decaimento entre 250 e $500{ }^{\circ} \mathrm{C}$. 
Esse intervalo de temperatura é característico para degradação de polímeros orgânicos típicos do processo de estabilização do lodo de esgoto e corresponde a maior fração de perda de massa. Para as amostras LEC 01, por ter menor tempo de estabilização, a perda de massa entre 200 a $500{ }^{\circ} \mathrm{C}$, está em cerca de $40 \%$, e para amostra LES04, nessa mesma faixa de temperatura, cerca de 17\%. Este comportamento indica uma decomposição térmica mais estável para amostra LES 04, o que sugere sua maior estabilidade nos ensaios de adsorção.

Isotermas de adsorção: Os dados de equilíbrio de adsorção para o adsorvente CEC01, Figura 3, não mostram adsorção do corante amarelo tartrazina, conforme os valores negativos da quantidade adsorvida.

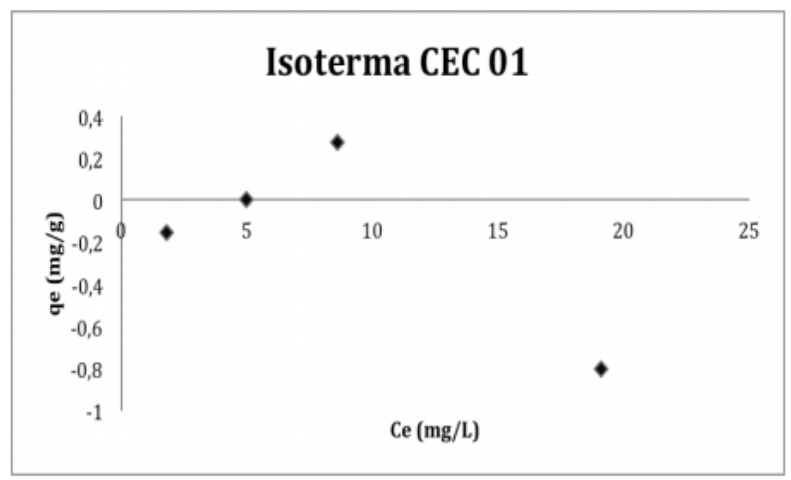

Figura 3- Isotermas de equilíbrio de adsorção do corante sobre o adsorvente CEC01.

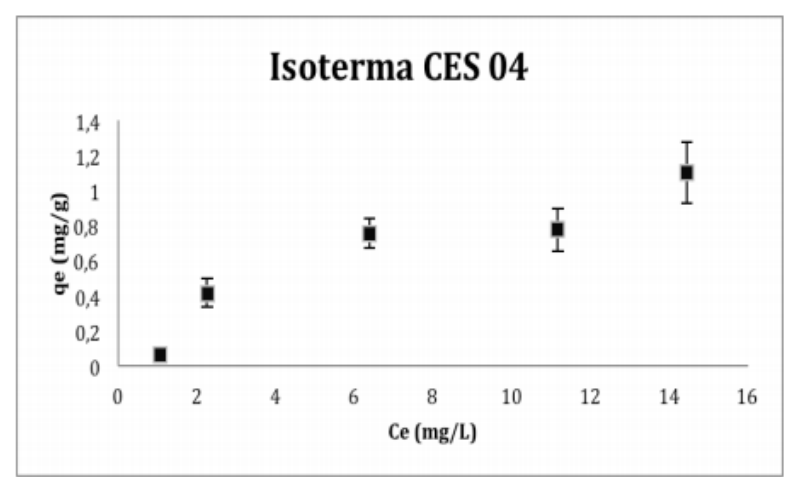

Figura 4- Isotermas de equilíbrio de adsorção do corante sobre o adsorvente CES04.

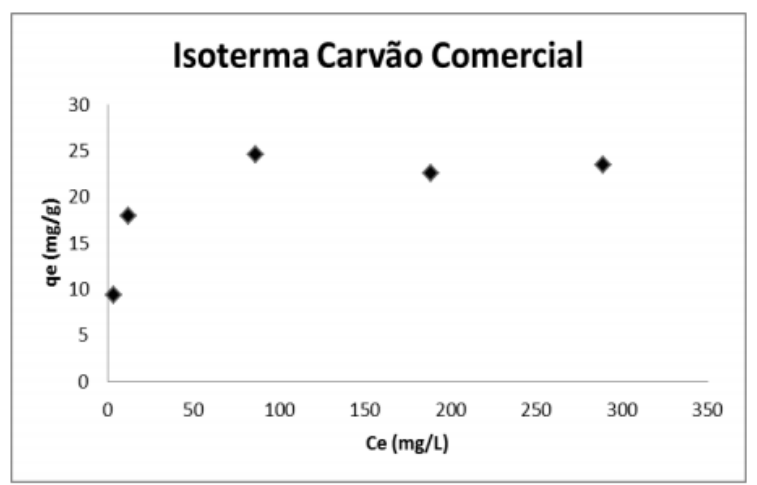

Figura 5- Isotermas de equilíbrio de adsorção do corante sobre o carvão comercial.

Esse comportamento sugere que material inorgânico presente na amostra foi lixiviado durante os ensaios, contaminando a solução de partida. Essa instabilidade deve estar 
associada ao tempo de desidratação do seu precursor (LEC01) no leito de secagem, que parece não ter sido suficiente para estabilizar o lodo de forma adequada, conforme resultados da análise térmica, Figura 2. Foram realizados testes de adsorção com uma amostra do adsorvente obtido do lodo de esgoto da ETE-Subaé, Figura 4, e com carvão sintético comercial como amostra de referência, Figura 5.

Os dados de equilíbrio do carvão comercial se ajustaram melhor a Isoterma de Langmuir $\left(\mathrm{R}^{2}>0,99\right)$, e os dados do CES04 a isoterma de Freundlich $\left(\mathrm{R}^{2}>0,92\right)$. $\mathrm{O}$ modelo proposto por Freundlich descreve melhor sistemas não ideais e em superfícies não homogêneas, compatível ao adsorvente CES04, ou seja, um material completamente heterogêneo. Os valores obtidos para máxima quantidade adsorvida $\left(\mathrm{q}_{\mathrm{m}}\right)$ para CES04 e carvão comercial foram 1,39 e 23,58 $\mathrm{mg} \mathrm{g}^{-1}$, respectivamente, Tabela 2. Apesar do baixo resultado obtido pelo adsorvente CES04, o adsorvente preparado neste trabalho mostra-se com um material em potencial quando comparado com outros da literatura (Banerjee, 2013).

Tabela 2 - Parâmetros das isotermas dos modelos de Langmuir e Freundlich.

\begin{tabular}{l|lll|lll}
\hline & Langmuir & & & Freundlich & \\
\hline Amostra & $\mathrm{q}_{\mathrm{m}}(\mathrm{mg} / \mathrm{g})$ & $\mathrm{K}_{\mathrm{L}}$ & $\mathrm{R}^{2}$ & $1 / \mathrm{n}$ & $\mathrm{K}_{\mathrm{F}}$ & $\mathrm{R}^{2}$ \\
\hline CES 04 & 1,39 & 0,17 & 0,8610 & 0,48 & 0,29 & 0,9249 \\
Comercial & 23,58 & 0,32 & 0,9987 & 0,19 & 8,97 & 0,7924 \\
\hline
\end{tabular}

\section{CONSIDERAÇÕES FINAIS}

O adsorvente CEC01 não se mostrou eficiente na adsorção do corante amarelo de tartrazina, pois material inorgânico presente na amostra foi lixiviado durante os ensaios. $\mathrm{O}$ adsorvente CES04, obtido de uma lodo mais estável, mantém sua estabilidade na remoção do corante tartrazina em solução aquosa, mesmo sem nenhum tipo de tratamento químico. Os dados de equilíbrio para a adsorção da tartrazina sobre o CES04 se ajustam melhor ao modelo matemático de Freundlich, diferentemente do dados de equilíbrio obtidos utilizando o carvão comercial que se ajustaram ao de Langmuir.

\section{REFERÊNCIAS}

BANERJEE, S.; Chattopadhyaya, M. C.; Adsorption characteristics for the removal of a toxic dye, tartrazine from aqueos solution by a low cost agricultural by-product. Arabian Journal of Chemistry, 2013.

DOTTO, G. L.; VIEIRA, M. L.; GONÇALVES, J. O.; PINTO, L. A. Remoção dos corantes azul brilhante, amarelo crepúsculo e amarelo tartrazina de soluções aquosas utilizando carvão ativado, terra ativada, terra diatomácea, quitina e quitosana: estudos de equilíbrio e termodinâmica. Quim. Nova, Vol. 34, No. 7, 1193-1199, 2011.

MITTAL, A.; Kurup, L; Mittal, J.; Freundlich and Langmuir adsorption isotherms and kinetics for the removal of tartrazine from aqueous solutions using hen feather. Journal of Hazardous Materials, 146 (2007) 243-248.

REIS, G. S.; Lima, É. C.; Sampaio, C. H.; Produção de carvão ativado a partir de lodo de esgoto doméstico e sua aplicação na adsorção do corante preto remazol 5 em solução aquosa. e-xacta. Belo Horizonte. Vol. 8, n. 2 (2015), p. 15-23. 